\title{
Etiology of thyroid disorders in children: A cross sectional study in a tertiary care centre
}

\author{
G Bala Bhaskara Reddy
}

Associate Professor, Dept. of Pediatrics, Fathima Institute of Medical Sciences, Kadapa, Andhra Pradesh, India

*Corresponding Author: G Bala Bhaskara Reddy

Email: balabhaskareddy@ rediffmail.com

\begin{abstract}
Introduction: One of the most commonly encountered hormonal disturbances in the pediatric age group is thyroid dysfunction, out of which hypothyroidism the most common one. This study was done to assess the clinical and the etiology of thyroid disorder in children.

Materials and Methods: 118 children from the ages 0 to 15 with suggestive features of hypothyroidism such as prolonged jaundice of the newborn, features of cretinism, physical and mental growth retardation, obesity, constipation were included into the study. Apart from demographic and familial details, blood was collected for the detection of T3, T4 and TSH.

Results: There was a slight preponderance of females over males (1.4:1 ratio). Out of the total children included in the study, euthyroid was seen in $65.3 \%, 27.1 \%$ had hypothyroid and $7.6 \%$ had hyperthyroidism. Most of them (66\%) were non goitrous hypothyroidism, where as $12 \%$ cases were hypothyroid with goiter. $2 \%$ were with goiter among the hyperthyroid cases and $20 \%$ without goiter. Out of the causes of thyroid disorders, the most common was acquired hypothyroidism in all the cases. Goitre was seen in 11 of the patients with euthyroid, 5 in patients with hypothyroid and in 1 patient with hyperthyroid.
\end{abstract}

Conclusion: Understanding the risk factors, signs and symptoms are very essential to prevent this condition. Education to the parents is also needed.

Keywords: Hypothyroisim, Hyperthyroidism, Thyroid dysfunction, Children.

\section{Introduction}

One of the most commonly encountered hormonal disturbances in the pediatric age group is thyroid dysfunction, out of which hypothyroidism the most common one. After diabetes mellitus, thyroid dysfunction is the most common endocrine disorder in the children throughout the world. ${ }^{1}$

Thyroid hormones are responsible for the increase in oxygen consumption, stimulation of protein synthesis, carbohydrate, lipid as well as lipid metabolism, and also influence various other enzymatic activities and growth factor of the body. They have a vital importance in the brain development, where they promote cell growth and differentiation and induce the neurotransmitter function ${ }^{2}$. There deficiency causes a profound effect on the metabolism, growth and development. ${ }^{3}$

The thyroid dysfunction is usually age related, organ and tissue related. If the deficiency is during the early life or during the fetal stages, it can lead to irreparable damage including the neurocognition. ${ }^{2}$ After the age of three years, since the brain development is complete, it can lead to stunted or slow growth and delayed skeletal maturation. ${ }^{4}$

The prevalence of the thyroid disorders range from region to region. It had been reported worldwide, while in India, Iran and Bangladesh, a higher prevalence has been observed. ${ }^{5}$ It has been reported that around 1.6 billion people of the world are at risk. ${ }^{6}$ In India, about 42 million people suffer from thyroid related diseases. The prevalence in children is estimated to be $0.07-1.7 \%$ and is steadily increasing. ${ }^{7}$

Hyperthyroidism occurs when the production of triiodothyronine (T3) and Thyroxine (T4) is in excess, while hypothyroidism is when these two levels are lower than required. One of the most common causes of thyroid disorders in iodine deficiency. ${ }^{7,8}$ In 1983, India adopted the salt ionization program, there has been a steady decline of iodine related hypothyroidism. ${ }^{9-11}$

This study was done to assess the clinical and the etiology of thyroid disorder in children.

\section{Materials and Methods}

This cross sectional hospital based study was done by the department of pediatrics at Fathima institute of medical sciences, Kadapa over a period of Between August 2016 to July 2019. This study was cleared by the Institutional Ethical Committee and Informed consent was obtained from the parents of all the patients after explaining the nature of study in detail to them. In the unavailability of the parent, the consent was given by the legal guardian. 118 children from the ages 0 to 15 with suggestive features of hypothyroidism such as prolonged jaundice of the newborn, features of cretinism, physical and mental growth retardation, obesity, constipation were included into the study. Patients who were already being treated for thyroid disorders were excluded from the study. Those who refused to give informed consent also were excluded from the study.

Detailed demographic data such as age, sex, height weight, BMI, salt intake per day, temperature, blood pressure, familial history of hypo or hyper thyroidism etc were taken. They were all subjected to thorough medical and clinical examination, and symptoms and clinical features were carefully noted. Examination of the thyroid gland was done and categorized according to the WHO guidelines. ${ }^{12}$

Thyroid profile which included Thyroid stimulating hormone (TSH), T4 and T3 was done for all the children. The Fasting blood cted by venous puncture and allowed to clot. The serum collected was tested for T3, T4 and TSH, 
using ELISA. Complete blood picture, hemoglobin estimation was done for all the samples.

\section{Results}

118 children were suspected to have thyroid dysfunctions based on their clinical symptoms and conditions. There was a slight preponderance of females over males (1.4:1 ratio). The most common age group to be affected was 1-3 years where 39 children were affected $(33.1 \%)$, out of which 17 were boys $(34.7 \%)$ and 22 were girls $(31.9 \%)$. This was followed by 6-9 years 27 children $(22.9 \%)$, out of which 12 $(24.5 \%)$ were boys and $15(21.7 \%)$ were girls. (Table 1$)$

Table 1: Gender and age wise distribution of patients

\begin{tabular}{|l|c|c|c|}
\hline Age & Boys & Girls & Total \\
\hline$<1$ month & $1(2 \%)$ & $1(2 \%)$ & $2(1.7 \%)$ \\
\hline $1-12$ months & $2(4.1 \%)$ & $6(8.7 \%)$ & $8(6.8 \%)$ \\
\hline $13-36$ months & $17(34.7 \%)$ & $22(31.9 \%)$ & $39(33.1 \%)$ \\
\hline $37-72$ months & $9(18.4 \%)$ & $13(18.8 \%)$ & $22(18.6 \%)$ \\
\hline $73-108$ months & $12(24.5 \%)$ & $15(21.7 \%)$ & $27(22.9 \%)$ \\
\hline $109-144$ months & $7(14.3 \%)$ & $11(15.9 \%)$ & $18(15.3 \%)$ \\
\hline$>144$ months to 15 years & $1(2 \%)$ & $1(1.4 \%)$ & $2(1.7 \%)$ \\
\hline Total & $49(41.5)$ & $69(58.5 \%)$ & $118(100 \%)$ \\
\hline
\end{tabular}

Out of the total children included in the study, euthyroid was seen in $77(65.3 \%), 32$ had hypothyroid (27.1\%) and 9 had hyperthyroidism (7.6\%). (Fig. 1)

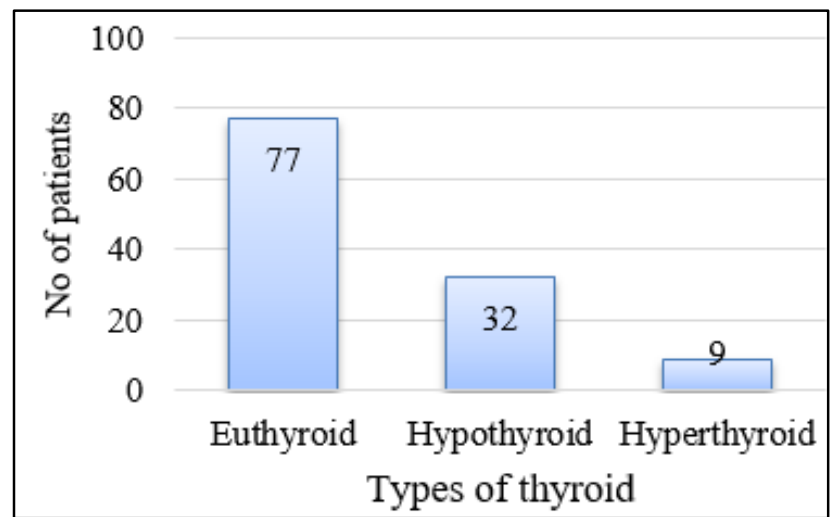

Fig 1: Classification of thyroid disorders among the patients

Out of the 41 cases of hypothyroid and hyperthyroid conditions, most of them (27) were non goitrous hypothyroidism (66\%), where as 5 cases were hypothyroid with goiter (12\%). Out of the 9 cases of hyperthyroid, 1 was with goiter $(2 \%)$ and 8 were without goiter (20\%). (Fig: 2)

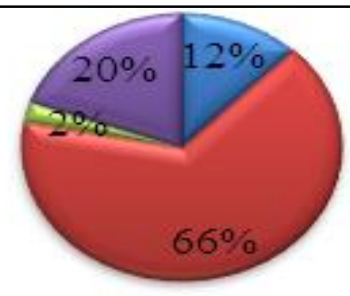

Goitrous hypothyroidism

Non goitrous hypothyroidism

Goitrous hyperthyroidism

Non goitrous hyperthyroidism

Fig 2: Types of hypothyroid and hyperthyroid

The most common symptom seen among the patients was lethargy in 28 children $(23.7 \%)$, followed by pallor in 21 patients $(17.8 \%)$. Dry skin was seen in 16 patients (13.6\%) and constipation in 12 (10.2\%). (Fig. 3) 


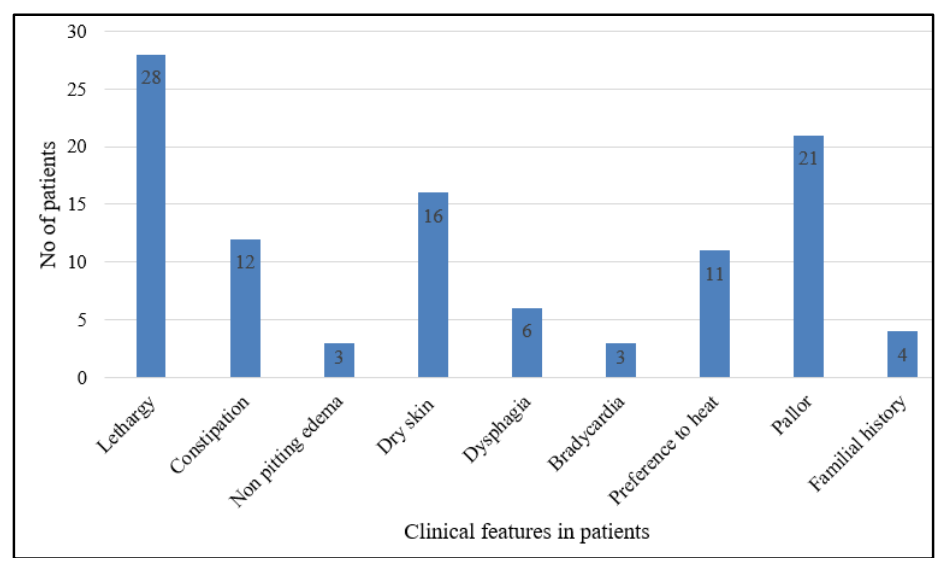

Fig 3: Clinical features

Out of the causes of thyroid disorders, the most common was acquired in all the cases. Goitre was seen in 11 of the patients with euthyroid, 5in patients with hypothyroid and in 1 patient with hyperthyroid (Table 2).

Table 2: Causes of thyroid disorders

\begin{tabular}{|l|c|c|c|c|}
\hline Disorder & Euthyroid & Hypothyroid & Hyperthyroid & Total \\
\hline Goitre & $11(9.3 \%)$ & $5(4.2 \%)$ & $1(0.8 \%)$ & $17(14.4 \%)$ \\
\hline Congenital & $1(0.8 \%)$ & $2(1.7 \%)$ & $0(0)$ & $3(2.5 \%)$ \\
\hline Acquired & $60(50.8 \%)$ & $23(19.5 \%)$ & $8(6.8 \%)$ & $91(77.1 \%)$ \\
\hline Autoimmune & $5(4.2 \%)$ & $2(1.7 \%)$ & $0(0)$ & $7(5.9 \%)$ \\
\hline
\end{tabular}

\section{Discussion}

41 of the 118 cases who had symptoms of thyroid disorders had hypo or hyperthyroidism. Out of these, a higher female to male ratio was observed of $1.4: 1$. A similar observation was made in a study by Yelluri, where a 2:1 ration was observed. ${ }^{12}$ Similar preponderance of females over males were seen in other similar studies by Kapil et al (2.9:1), Hunter et al (2.8:1) and Shah et al (3:1). Unnikrishnan et al, in a similar study in adults reported $54.7 \%$ of the patients to be females. ${ }^{13-16}$ In another study, 8:1 female to male ratio was observed. ${ }^{17} \mathrm{~A}$ study by Onyeruika et al reported a ratio pf 4:1, Ogbera and Kuku reported 5:1 ration in adults. ${ }^{7,18}$ However in a study by Jaja et al, 1.7 time more incidence was seen in males. ${ }^{19}$

Out of the 41 cases of hypothyroid and hyperthyroid conditions, most of them (27) were non goitrous hypothyroidism $(66 \%)$, where as 5 cases were hypothyroid with goiter $(12 \%)$. Out of the 9 cases of hyperthyroid, 1 was with goiter $(2 \%)$ and 8 were without goiter (20\%). A study by Desai (1997) reported out of 800 children with suspected thyroid disorders, $79 \%$ had hypothyroid, both goitrous and non goitrous, while only $19 \%$ of them had euthyroid goiters and $2 \%$ hyperthyroidism, ${ }^{4} 93 \%$ of hypothyroidism was reported by Singh et al. ${ }^{20}$ Studies by Desai, Shah et al, Hunter et al and Marwaha et al also reported similar results which ranged from $2.5-10 \% .^{4,14,15,21}$

In the present study, only $7.6 \%$ of the patients had hyperthyroidism. This was corroborated by a study by Singh et al, who reported an incidence of $6.1 \% .^{20}$

The most common age group to be affected was 1-3 years where $33.1 \%$ of the children were affected followed by 6-9 years with $22.9 \%$ affected. A prevalence of a higher age group was observed in a study by Onyeruika, where the mean age group was 11.2 years. ${ }^{7}$ Much earlier in 1979, Laditan noted the mean age group in children to be affected was 5.4 years. $^{22}$

The youngest patient to have hypothyroidism was 21 hours old, female. There were 2 children below the age of 1 month with hypothyroisim in the present study. A study by Oyenusi et al reported the youngest patient to be 7 hours. ${ }^{23}$ All these children in our study had mothers with hypothyroidism.

In the present study, $66 \%$ of the 41 cases had non goitrous hypothyroidism, where $12 \%$ had hypothyroid with goiter. Out of the 9 cases of hyperthyroid, 1 was with goiter $(2 \%)$ and 8 were without goiter $(20 \%)$. This was similar to a study by Singh et al. ${ }^{20}$

In the present study, goiter was seen in $14.4 \%$ of the cases out of which $9.3 \%$ were from euthyroid cases, $4.3 \%$ in patient with hypothyroid and $0.8 \%$ in patients with hyperthyroid. Most common cause was acquired seen in $78.8 \%$ of the cases. Around $65 \%$ of the cases were euthyroid. In a study by Yelluri et al, ${ }^{13} 58.3 \%$ of the cases were euthyroid as was seen with Shah et al with $56 \%$ of their cases. ${ }^{15}$ In a study by Singh et al, $10 \%$ of the patients were seen with goiter, ${ }^{20}$ while Desai reported about $38 \%$ of children with goiter in thyroid related abnormalities. ${ }^{4}$

Congenital hypothyroidism was seen in 2 cases in the present study, amounting to $1.7 \%$. However a very high incidence of congenital hypothyroidism was seen in many studies. A study by Oyenusi et al reported a $46.7 \%$ 
incidence of congenital hypothyroidism in their study in Nigeria. In places where there is iodine deficiency, most of the reasons for thyroid dysfunctions are thyroid dysgenesis, ectopic thyroid or athyreosis. ${ }^{24}$

\section{Conclusion}

In order to optimize development and growth of the children, it is important to identify the presence of thyroid disorders, early. Thus it is imperative to understand the risk factors, the signs and symptoms, the laboratory results and accurate diagnosis. The parents are also advised to recognize any abnormalities in the children and seek immediate care as thyroid disorders need long term care and therapy.

\section{Source of funding}

None.

\section{Conflict of interest}

None.

\section{References}

1. Becker KL, Nylen ES, Snider RH. Endocrinology and the endocrine patient. In: Becker L, Ronald CK, Rebar RW. eds, Principles and practice of endocrinology and metabolism. 3rd ed Lippincott, Williams and Wilkins, 2002:82-5.

2. Desai MP. Thyroid function in children. JAPI. 2011;59:35-42.

3. Desai MP. Disorders of thyroid gland. In: Pathasarathy A, ed. I A P Textbook of Pediatrics, 4th ed. New Delhi, Japee Brothers Medical Publishers Ltd, 2009, 931-5.

4. Desai MP. Disorders of thyroid gland in India. Ind J Pediatr 1997;64:11-20.

5. Rendon-Macias ME, MoralesGracia I, Huerta- Hermandez E, Silva-Batalla A, Villasis-Keever MA. Birth Prevalence of Congenital Hypothyroidism in Mexico. Paediatr Perinatal Epidemiol 2008;22(5):478-85.

6. Alam Khan, M. Muzaffar Ali Khan, Shamim Akhtar, 2002. Thyroid Disorders, Etiology and Prevalence. J Med Sci 2002;2:89-94

7. Onyiruika AN, Abiodun PO, Onyiruika LC. Thyroid Disorders in Childhood and Adolescence: Analysis of clinical data and management challenges in patients seen in a Nigerian Teaching Hospital. Greener J Med Sci 2012;2(2):45-50

8. Fisher D. Next generation newborn screening for congenital hypothyroidism? J Clin Endocrinol Metab 2005;90(6):3797-9.

9. Sood A, Pandav CS, Anand K, Sankar R, Karmarkar MG. Relevance and importance of universal salt iodization in India. Natl Med J India 1997;10:290-3.
10. Dodd NS, Godhia ML. Prevalence of iodine deficiency disorders in adolescents. Indian J Pediatr.1992;59:585-91

11. World Health Organization, International Council for Control of Iodine Deficiency Disorders, UNICEF. Indicators for assessing iodine deficiency disorder and their control through salt iodization. Geneva: World Health Organization. 1994, 14

12. Yelluri SK. Incidence and etiology of thyroid disorders in children. Int J Contemp Pediatr 2016;3:593-6.

13. Kapil U, Saxena N, Ramachandran S, Balamurugan A, Nayar D, Prakash S. Assessment of iodine deficiency disorders using the 30 cluster approach in the National Capital Territory of Delhi. Indian Pediatr 1996;33:1013-7.

14. Hunter I, Greene SA, McDonald TM, Morris AD. Archieves: Diseases of childhood September. 2000;83:207-10.

15. Shah NA, Modi PJ, Bhalodia JN, Desai NJ. Evaluation of thyroid diseases by hormonal analysis in pediatric age group. National J Med Res 2013;3(4):367-70.

16. Unnikrishnan AG, Menon UV. Thyroid disorders in India: An epidemiological Prospective. Indian J Endocrine Metab 2011;(12):78-81.

17. Jaksic J, Dumic M, Filipovic B, Ille J, Cvijetic M, Gjuric G Thyroid diseases in a school population with thyromegaly. Archives of Dis in Childhood 1994;70:103-6.

18. Ogbera AO, Kuku SF. Epidemiology of thyroid diseases in Africa. India J Endocrinol 2011;5(6): 82-8.

19. Jaja T, Yarhere IE. Clinical characteristics of children and adolescents with thyroid disorders seen at the University of Port Harcourt Teaching Hospital: A five - year review. Niger $J$ Paediatr 2014;41:302-6.

20. Amitabh Singh, Charul Purani, Anirban Mandal, Kishor M Mehariya, Rashmi Ranjan Das. J Clin Diagn Res 2016;10(2):1-4.

21. Marwaha RK, Sankar R, Magdum M. Clinical, biochemical and cytomorphological observations in juvenile chronic lymphocytic thyroiditis. Indian Pediatr 1998;35: 967-73.

22. Laditan AAO, Johnson AOK. Thyroid gland disorders in African Children. J Natl Med Assoc 1979;71(2): 139-41.

23. Oyenusi EE, Ajayi EO, Akeredolu FD, Oduwole AO. Pattern of thyroid disorders in children and adolescents seen at the Lagos University Teaching Hospital, Nigeria, over a 10-year period. Niger Med J 2017;58:101-06.

24. Mark P. J. Vanderpump. The epidemiology of thyroid disease. British Med Bull 2011;99(1);39-51.

How to cite this article: Reddy GBB. Etiology of thyroid disorders in children: A cross sectional study in a tertiary care centre. Int J Med Paediatr Oncol 2019;5(4):117-20. 